The Northern Review

yukoncollege.yk.ca/review

\title{
Toxic Legacies, Slow Violence, and Environmental Injustice at Giant Mine, Northwest Territories
}

\author{
John Sandlos and Arn Keeling
}

\begin{abstract}
For fifty years (1949-99) the now-abandoned Giant Mine in Yellowknife emitted arsenic air and water pollution into the surrounding environment. Arsenic pollution from Giant Mine had particularly acute health impacts on the nearby Yellowknives Dene First Nation (YKDFN), who were reliant on local lakes, rivers, and streams for their drinking water, in addition to frequent use of local berries, garden produce, and medicine plants. Currently, the Canadian government is undertaking a remediation project at Giant Mine to clean up contaminated soils and tailings on the surface and contain 237,000 tonnes of arsenic dust that are stored underground at the Giant Mine. Using documentary sources and statements of Yellowknives Dene members before various public hearings on the arsenic issue, this paper examines the history of arsenic pollution at Giant Mine as a form of "slow violence," a concept that reconfigures the arsenic issue not simply as a technical problem, but as a historical agent of colonial dispossession that alienated an Indigenous group from their traditional territory. The long-term storage of arsenic at the former mine site means the effects of this slow violence are not merely historical, but extend to the potentially far-distant future.
\end{abstract}

The abandoned Giant Mine has always been an emblem of prosperity in Yellowknife, Northwest Territories, a visible reminder of the city's origins as a gold mining town. In recent years, however, Giant Mine has also come to symbolize the destructive long-term environmental impacts of mining as the public has become more aware of arsenic contamination the mine left behind. Beginning in 1949, and continuing for the next fifty years, mine owners Giant Yellowknife Gold Mines (1948-1991) and Royal Oak Mines 
(1991-1999) spewed arsenic trioxide, a highly toxic by-product of goldore roasting, into the air and waters surrounding the mine. Arsenic also entered the surrounding environment through tailings impoundments and treated mine water deposited into a local creek that drained into Great Slave Lake. Over the years, the company partially reduced emissions with the installation of electrostatic precipitators and with the construction of a "bag house" filter in 1959, but arsenic continued to be released to the atmosphere for decades afterwards.

While mitigating the worst air pollution in the short term, this technological solution meant that over the next fifty years the company collected 237,000 tonnes of arsenic trioxide dust that it stored underground in fourteen old mining stopes or specially built chambers. In 1999, Royal Oak went into receivership and the Canadian government inherited the liabilities at what is increasingly described as Canada's worst longterm contaminated site (Sandlos and Keeling 2012; Auditor General of Canada 2012). The sheer scope of current contamination problems can be measured partly in the nearly billion-dollar cost estimated for remediating the site, including surface clean-up and stabilizing (through freezing) the underground arsenic chambers (CBC News 2013).

The story of Giant Mine is not only one of failed technological solutions and the dangers of short-term thinking. The history and contemporary legacy of Giant Mine underlines the intersections of environmental pollution and racial inequality - in this case, the impact of pollution on the Yellowknives Dene First Nation, the area's Indigenous people. The historical geography of arsenic contamination in the Yellowknife region reveals the unequal "pathways of exposure" of Yellowknives Dene people to arsenic. While airborne arsenic and landscape contamination potentially affected both the Indigenous and settler populations alike, Yellowknives Dene people were uniquely exposed to contamination because of their reliance on local land and water resources for their subsistence. This pathway of exposure led to specific (and tragic) health consequences for some local Dene individuals, but just as importantly, pervasive arsenic pollution has also produced a persistent, long-term landscape of exposure for Dene land and communities. For the Yellowknives Dene, the environmental injustice of arsenic contamination is reflected not only in stories of sickness and death (as tragic as these were), but also in the profound feeling of alienation from a landscape that had, in effect, been colonized as a pollution sink for southern economic interests.

Traditional environmental justice scholarship has emphasized the distributional aspects of environmental harms, particularly through the 
siting of industrial facilities in racially segregated or poor communities. More recently, however, scholars and activists have highlighted broader historical and geographical processes-class formation, technological development, regulatory science, and the political economy of resource development - that contribute to environmental injustices (Walker 2009; Nash 2006; Murphy 2008; Mittman et al. 2004). Highlighting the roots of environmental injustice in these broader processes, literary scholar Rob Nixon (2011) has argued that toxic contamination is a form of "slow violence" among the poor, often difficult to recognize in comparison to more immediate and spectacular forms of violence and displacement. Nixon's account of Indigenous activism and writing surrounding episodes of toxic contamination highlights the challenges of representing the "pervasive but elusive violence of delayed effects" from pollution (Nixon 2011: 3).

This article examines how the slow violence of toxic contamination at Giant Mine produced environmental injustice in a northern Indigenous context. As with other Indigenous communities in North America, at Yellowknife pollution and landscape degradation intersected with the legacies of colonialism and the geographies of social inequality, highlighting the ongoing and mutually reinforcing quality to the effects of each in producing environmental injustice (Langston 2010; McGregor 2009; Keeling and Sandlos 2009; Mascarenhas 2007; Rosier 2006). The "wastelanding" of Navajo territory by uranium mining in the United States Southwest, documented by Traci Brynne Voyles, powerfully illustrates these links. Voyles situates the production of contaminated Indigenous lands and bodies within processes of settler colonial territorialization that discursively and materially reconfigured Navajo lands as both empty "wastelands" and as resource frontiers amenable to modern industrial exploitation and pollution (Voyles 2015). In this account, the politics of contamination is necessarily a politics of land as well as a politics of bodily exposure to toxins, whether acute or chronic. Landscapes of exposure, in this view, map onto landscapes of dispossession. As in the Navajo case, for Dene people the politics of pollution and health is inextricably intertwined with the land (Parlee et al. 2007; Gibson and Klinck 2005). Toxicity and contamination are best understood as exposures registered not only at the level of individual bodies (as in, say, a dose-response model), but also as an alienation from land and culture, a form of dispossession and loss of health tied to the inability to safely and confidently use local land and water resources (cf. Schlossberg and Carruthers 2010; Goodall 2006; Kirsch 2001 , 2006). Drawing on historical documents, community-based research, 
and public hearings and workshops, our research with the Yellowknives Dene underscores how, in their struggles for recognition of their Giant Mine pollution experience, they draw connections between the legacies of colonial dispossession, land degradation, and the slow violence of toxic contamination faced by the community in the present-and, potentially, the long-term future. For the Yellowknives Dene, remediating Giant Mine not only entails a technical solution to the arsenic contamination problem, but must also address colonial histories of dispossession and displacement. Healing the land, and providing compensation for past and future losses of water and local resources, has become an important means to reconcile with the environmental injustices of their recent past.

\section{Poisoning the Land and People}

The arsenic that ultimately contaminated the land and people of Yellowknife was not an introduced element, but rather it was mobilized from its geological context in local rock. Although the gold deposits initially mined in the area contained no arsenic, the ore bodies at Giant Mine contained gold primarily in arsenopyrite formations. The bulk of this arsenic-laden (also termed refractory) ore required crushing and roasting before cyanidation in order to extract and recover minute particles of gold from the mineral matrix; this roasting process also produced the highly toxic compound arsenic trioxide, which formed a fine white dust as it condensed. As Giant Mine moved to full production in the late 1940s, arsenic was rapidly mobilized into the local environment through both roaster stack emissions and tailings. In its first few years of operation, before the first pollution controls were implemented, Giant Mine released an incredible 7.26 tonnes per day of arsenic trioxide from its stack; nearby Con Mine, with a slightly different roasting process, contributed two to three tons more (De Villiers and Baker 1970, 3-5).

The arrival of Giant Mine coincided with dramatic social, cultural, and economic changes experienced by the Yellowknives Dene (Weledeh) people. The Yellowknives Dene have a long history of occupation and traditional use of the land and resources of the north Great Slave Lake region and barrenlands to the east. Though they participated in the fur trade and later adhered to Treaty 8 with the Canadian government in 1900, it was mineral exploration and development activities beginning in the 1930s that brought extensive changes to these land-based lifeways and settlement patterns (Yellowknives Dene First Nation 1997; Abel 1993). As Elder Michelle Paper has stated, "people love the land but mining has changed the land and made it dangerous" (Alternatives North 2011). 
Paper was among the last elders who remembered life before the mining era in the 1930s, when the Yellowknives remained relatively isolated from outsiders, their small camps on Yellowknife Bay located away from the main fur trade shipping routes along the Mackenzie and Slave rivers. Although some Yellowknives (including Paper) found work among the prospectors and miners that flooded the area in the mid-1930s, the advent of the mining era represents the signature colonial moment in this First Nation's history, a time when the rapid influx of settlers irrevocably altered the land and produced pollution that undermined the local economy based on fishing, hunting, trapping, and gathering.

The mining company's comprehensive pollution of the local environment worked in tandem with socio-economic marginalization to inflict tragedy on the Yellowknives Dene community (later named Ndilo) adjacent to Yellowknife on Latham Island. Located a short distance from the mine across Back Bay (Fig. 1), this predominantly Indigenous settlement emerged as some Dene people, who had long occupied the area seasonally for fishing, hunting, and berry picking, began to settle near the town of Yellowknife (Yellowknives Dene First Nation 1997). Initially an informal settlement, Ndilo (and its sister settlement Dettah further to the south across Yellowknife Bay) remained unserviced long after the new municipal government provided sewerage and water supplies to Yellowknife proper (at a new townsite located farther from the mine) in the 1940s. Ndilo residents relied on snowmelt, lake, and stream water rather than on municipal supplies.

Arsenic trioxide is undetectable by taste and smell and does not readily degrade. In the absence of cleansing rains in the region's dry environment, the arsenic dust that the company dispersed from the Giant Mine stack accumulated on the land (in summer) and especially on snow during the long, cold northern winters. In the spring, a pulse of snowmelt mobilized months' worth of arsenic deposition, carrying it into local surface waters (Kay 1968, 655-657). This pollution, combined with the Yellowknives' reliance on snowmelt for drinking water, resulted in at least one confirmed case of acute arsenic poisoning: the April 1951 death of a two-year-old Dene boy on Latham Island. Local health authorities subsequently posted signs around Latham Island and published warnings about the pollution in the local newspaper, but such English-language warnings were unlikely to reach Dene people who could not speak or read English (at this time, few would have received formal schooling), and who, in any case, lacked ready access to alternative water supplies (Sandlos and Keeling 2012). 


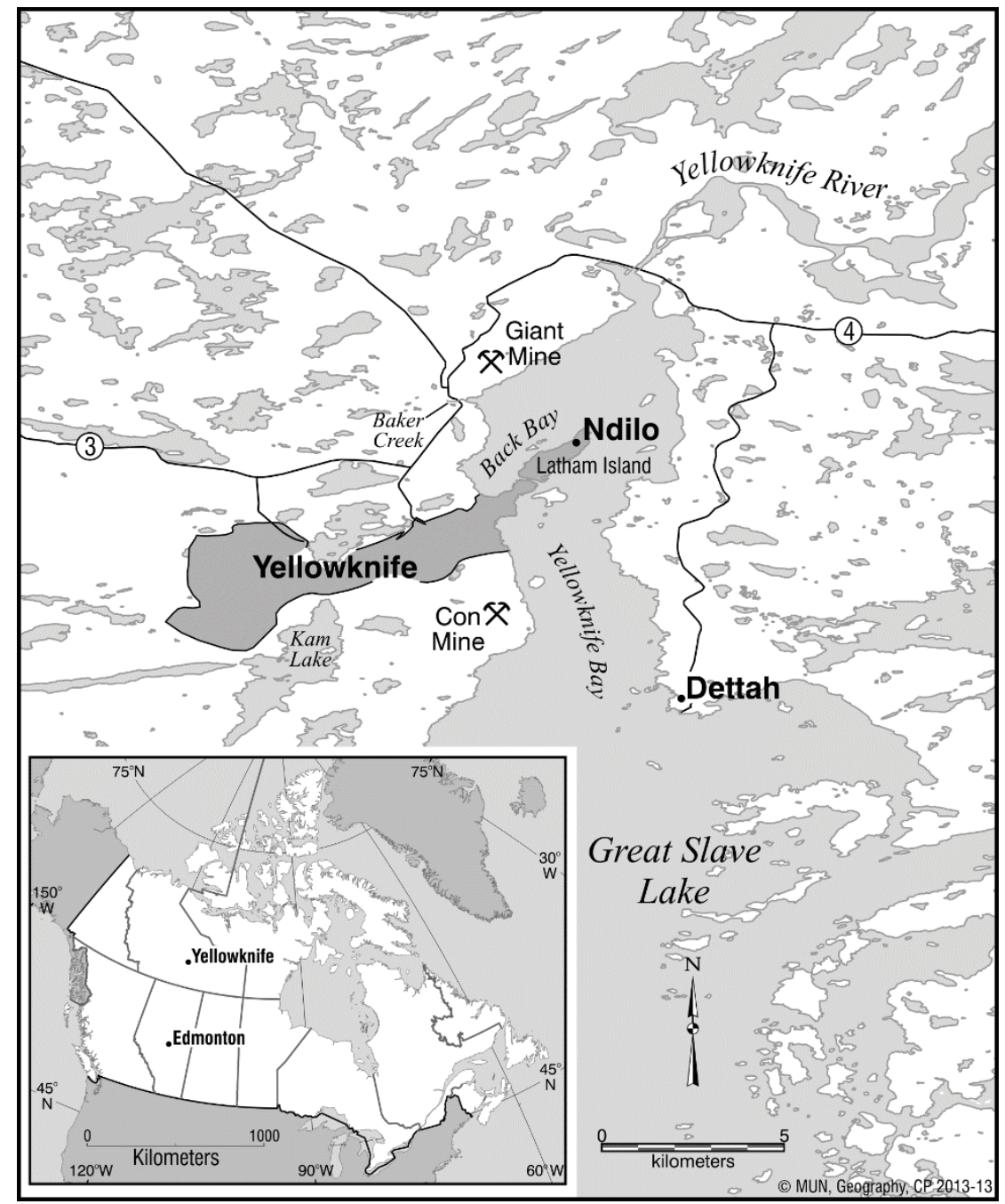

Figure 1. Yellowknife, Giant Mine, and the Dene settlements of Ndilo and Dettah. Map by Charlie Conway.

Yellowknives Dene oral history accounts suggest other deaths, as well as the sickening of elders in particular. Animals, too, were affected: Dene Elders recall sled dogs that died or lost their hair after travelling on the land, and settler communities in Yellowknife also testified to the poisoning of local domestic animals (Yellowknives Dene First Nation 1997, 52). Decades afterward, the sickness and death remained potent and painful memories for many Yellowknives Dene, and memories of the arsenic crisis 
of the 1950s form the core narrative of the community's encounter with gold mining. Although the precise dates and number of fatalities vary in oral testimonies, numerous sources recount the impact of the pollution and sickness on the community. For instance, at the September 2012 public hearings on the proposed Giant Mine Remediation Plan, former Chief Fred Sangris recounted,

[O]ur story goes back in 1950s, when one of the worst things that ever happened to us - and we still have good memories of it in our community; we still talk about it in Dettah and N'Dilo is that two (2) children, two (2) Dene children, lost their lives because somebody gave the mines a permit to go ahead and use many of the arsenic into the atmosphere and sulphur trioxide and arsenic in the land use permit. And then somebody else gave them a permit, water licence, to release a lot of ammonia into the water.

This really ... devastated our lives. Not only that two (2) Dene children lost their lives, but around Yellowknife Bay there were so many dead fish floating around the shorelines. Many of the old people who I heard stories from said they were crying, there may not be any fish around Yellowknife Bay. '51/'52 was the worst years for us.

And then in 1969, an Elder in N'Dilo passed away, mysteriously, very quickly passed away. The community asked that there be an autopsy. So the hospital here came to our aid and took a sample of her hair. She was poisoned to death. She had arsenic level in her hair that was ten (10) times higher than normal. She got poisoned from arsenic. (MVEIRB 2012a: 246-47)

In this period, for the Yellowknives Dene, the violence of contamination was anything but "slow." It was associated with the rapid invasion of their traditional territories by prospectors and gold miners, the establishment of mines and a settler community on lands long used by Dene for travel and resources, and the poisoning of their land and people beginning in the late 1940s. Social marginalization and environmental conditions combined to create a unique pathway of exposure to arsenic for Dene people. Public authorities, concerned with ensuring minimal expense and disruption to production for the mining companies, ignored the threats posed by arsenic contamination to Dene communities, settling instead on a strategy of ineffective warnings and minimal water-service provision. While the mine 
was forced, eventually, to reduce arsenic emissions, a significant amount of toxic material was still being loaded into the local environment through much of the 1950s (De Villiers and Baker 1970). Ultimately, uncertainty surrounding the subacute effects of arsenic exposure and adherence to a dose-response model of toxic exposures, which assumed that there was a safe level of arsenic for humans, allowed health official and regulators to overlook the potential health hazards of continual low-dose exposure. Regardless, maintaining gold production remained paramount, as public health officials ignored the frequent "spikes" in contamination associated with seasonal runoff and other pollution events.

As a result, subsequent decades saw the region become a landscape of chronic exposure through long-term arsenic contamination. In spite of haphazard pollution-control efforts and arsenic-exposure studies, controversy repeatedly flared over environmental pollution (Tataryn 1979). Episodes of hair testing and sampling, particularly of Yellowknives Dene children, contributed to a pervasive unease in the community about health and contamination, and in the 1970s, Yellowknives leaders protested having to pay for water trucked to the community so people would not drink contaminated water (Tataryn 1978). For the Yellowknives, the lands and waters that had sustained their lives and culture had become a source of danger, alienation, and uncertainty, compounding the negative effects of settlement life, residential schooling, hunting regulations, and the growth and modernization of Yellowknife that accelerated in the 1960s.

\section{Pollution, Remediation, and Memory}

In recent years, stories of the historical poisoning and contamination of the land have received renewed attention among the Yellowknives Dene, as the community confronts the massive challenge of remediating the closed and abandoned Giant Mine site (Sandlos and Keeling 2015). At public workshops, hearings, and in reports generated in conjunction with the environmental assessment of the remediation project, Yellowknives elders and other residents of the communities of Ndilo and Dettah articulated their experience of contamination from Giant Mine (e.g., Yellowknives Dene First Nation 2008). While the acute poisoning episode of the 1950s was often addressed, this testimony also emphasized the long-term, broad-scale impacts on Yellowknives' land and lifeways. In a traditional knowledge report compiled for the environmental assessment, many elders placed arsenic contamination into the wider context of mine development and the historical loss of access to land and resources (Yellowknives Dene First Nation Land and Environment Committee 2005). Elders recounted 
how, before mining, Dene people avoided disturbing the areas around the mine and the Yellowknife townsite, as they were known as productive areas for game and berry picking; these areas were now inaccessible and/or contaminated by the mine. The mouth of Baker Creek, a stream rendered virtually lifeless by mine waste during the mine's operation, was remembered as a productive fishing site. Isadore Sangris's thoughts on the impact of the mine are similar to many others:

As a result of the mines in the area, the land has been wasted, destroyed, and contaminated. Mining has occurred for more than fifty years and a lot of damage has occurred. The water is contaminated; rabbits and grouse are contaminated; the Dene people have become very cautious of eating tradition[al] foods because of the heavy contaminants in the water, land, and air. The contamination even destroys trees, marshes, habitat, and wild berries. All things that the Dene people want to use but cannot anymore. The land here cannot sustain them anymore. The Weledeh do not fish in the bay anymore; instead, they go to Wool Bay, they have to go to communities far from the mine to get their fish and water fowl. (Yellowknives Dene First Nation Land and Environment Committee 2005, 20)

In Sangris's and other Yellowknives' testimony, the intersection of the "slow violence" of arsenic contamination with the historical geographies of settler colonialism becomes powerfully apparent. In the often wideranging testimony of elders, mention of specific events such as the poisoning of the child and of sled dogs are interspersed with many other themes: treaty-making (and treaty obligations) with Canada, changes from seasonal occupancy to year-round settlement in the region, the discovery of gold and the arrival of prospectors, or the loss of access to land-based resources such as berries and moose. At the remediation plan hearings in 2012, Fred Sangris, for example, highlighted the impacts of arsenic on the fishing culture of the Yellowknives:

No Yellowknives Dene fish on that Yellowknife Bay todaynobody - because we're afraid we're going to be next ... getting cancer and getting that sickness. We have to go thirty (30) miles out to fish beyond Dettah. But nobody's compensate us for the devastation and-and toll it's taken on our lives in the community. Nobody apologized. Nobody. 
So a way of life that was promised to us in the treaties is no longer a promise. It's a violation of our treaty rights, because we fished in Yellowknife Bay, and we cannot fish there anymore. We get many of our medicine plants in Yellowknife Bay. They don't work anymore. Many of the sediment, the mud, 4 inches of it, in Yellowknife Bay, it's all arsenic.

For us, this great beautiful bay which used to support our lives, give us all the resources in our culture and our way of life, it's all gone, because the mine was so important to some people that it didn't really matter. Give them the permit. Give them water licence. Jobs are more important. But the Indian people who live here, took its toll, devastated. And we're still like that today. (MVEIRB 2012: 251)

In this account, the toxic effects of arsenic are not only acute or immediate, but chronic and intergenerational. It reflects a slow violence that, as Nixon $(2011,2)$ suggests, is "incremental and accretive, its calamitous repercussions playing out across a range of scales."

This sense of injustice does not merely encompass historical pollution issues, but also includes ongoing and future toxic legacies at Giant. To address the long-term problems associated with the 237,000 tonnes of arsenic trioxide buried at the site, the federal government proposed a controversial solution: freeze the underground arsenic chambers and maintain the site in perpetuity (Aboriginal Affairs and Northern Development Canada 2013). Long-term care and maintenance activities would include water pumping, water treatment, and periodic replacement of the freezing apparatus-all on an incomprehensible timeline of "forever," as formulated in the original remediation plan.

Yellowknife community activists and First Nations critics challenged this plan on a number of levels. First, they pointed out, there were few details on how the site would be funded, managed, and monitored beyond the implementation phase for a potentially unknown period of time. Second, the plan made only vague promises for "further research" towards the ultimate removal of the arsenic and restoration of the site (which was the preference of the Yellowknives Dene). Finally, critics raised the question of how public knowledge and understanding of the site's extreme hazards would be communicated to the far distant future. This concern dovetailed with questions surrounding the projected end land use at the former mine site. 
These latter issues emerged most forcefully in workshops and reports generated by a Yellowknife non-governmental organization, Alternatives North, often in collaboration with the Yellowknives Dene First Nation. At a community workshop on "perpetual care" arrangements at Giant Mine, Yellowknives elders linked the challenge of future management of permanent waste storage with their desire for recognition of the community's historical experience of contamination from the mine. The workshop report noted participants felt that "to do justice to future generations, we need to do justice to current generations. There needs to be an apology for the injustices of Giant Mine" (Alternatives North 2011, 14) Although recognizing the challenge of planning for permanently managing toxins at Giant, participants also urged the incorporation of Dene Indigenous knowledge into such plans, noting that the Dene had already occupied and cared for the land for thousands of years. ${ }^{1}$

The Yellowknives asserted the connections between their colonial past and the long-term future of the Giant Mine Remediation Project most emphatically during the 2012 public hearings of the environmental assessment. Speaking before the Mackenzie Valley Review Board, Chief Eddie Sangris suggested, "Giant Mine is the most significant environmental disaster in our people's history ... Yellowknives Dene must be acknowledged for their stake in this remediation project and the future of our land" (MVEIRB 2012b: 311). In an impassioned speech, Yellowknives Dene First Nation Councillor Mary Rose Sundberg discussed her concern about the long-term future contamination at Giant, in light of not only the Dene experience of colonialism and marginalization, but also their future in their traditional territory. Her testimony at the hearing also addressed the question-largely unconsidered in the government's remediation proposal-of toxic effects for future generations, inheritors of the mine's toxic legacy. "How do we communicate to our future generation? How do we tell them that this monster underground is dangerous, do not go there or even go near it?" she asked, highlighting the uncertain abilities of future governments to ensure maintenance and security of the site for hundreds, perhaps thousands of years into the future (MVEIRB 2012b, 345). Sundberg's (and others') interventions on the questions of perpetual care and communicating with future generations expanded otherwise banal projections of "future land use" at the remediated site into a complex and thorny discussion of how to both commemorate the past and represent the toxicity of the site through time. 


\section{Conclusion}

Like the activists and writers featured in Nixon's Slow Violence and the Environmentalism of the Poor, Yellowknives Dene interventions such as Sundberg's have disrupted official representations that seek to confine arsenic contamination to a nearly forgotten dark past, or to minimize responsibilities to future generations. Rather, they suggest the complex connections between the historical geographies of settler colonialism, resource development, and environmental injustice in Yellowknife. These forces converged during the early mining period to produce an unequal pathway of exposure to arsenic from Giant Mine to nearby Yellowknives Dene communities, who were not only located downwind of the mine's roaster stack, but whose history of colonization, social marginality, and land-based activities made them especially vulnerable to the toxic effects of arsenic pollution.

The Giant Mine case reinforces that a broader conception of environmental justice, beyond questions of waste siting or resource disputes, is critical to understanding the historical and contemporary implications of Indigenous environmental justice struggles in the Northand beyond. Recent scholarship is beginning to highlight how Indigenous environmental struggles are situated within and intersect with wider processes of colonial dispossession and socio-economic marginality. At the same time, the Yellowknives' cultural connections to land also form the basis for their contemporary political claims for recognition and redress (including compensation) for the environmental injustices of the past, present, and future of Giant (Sandlos and Keeling 2015). In highlighting the connections between colonialism and contamination, their advocacy directly addresses the representational challenges posed by the "slow violence" of permanent pollution. As the processes of remediation planning move forward at Giant Mine, it is critical for public authorities to reckon with these claims, or risk reproducing the social exclusion and environmental injustice that characterized the original mine development.

\section{Authors}

John Sandlos is associate professor in the Department of History at Memorial University of Newfoundland.

Arn Keeling is associate professor in the Department of Geography at Memorial University of Newfoundland. 


\section{Notes}

1. To some extent, these concerns were addressed in the report of the environmental assessment, which recommended the remediation project only be licensed for 100 years. Nevertheless, there remains no assurance the problem of arsenic storage and contamination will be resolved by that time.

\section{Works Cited}

Abel, K. 1993. Drum Songs: Glimpses of Dene History. Montreal: McGill-Queen's University Press.

Aboriginal Affairs and Northern Development Canada. 2013. "Remediation Plan." http://www.aadnc-aandc.gc.ca/eng/1100100027395/1100100027396.

Alternatives North. 2011. "From Despair to Wisdom: Perpetual Care and the Future of Giant Mine." Report on workshop held September 26-27, Dettah, NWT.

Auditor General of Canada. 2012. "Report of the Commissioner of Environment and Sustainable Development-Spring 2012." Ottawa: Public Works and Government Services.

CBC News online. 2013. "Yellowknife's Giant Mine cleanup costs to double." 27 March. http://www.cbc.ca/news/canada/north/yellowknife-s-giant-minecleanup-costs.html.

De Villiers, A.J., and P.M. Baker. 1970. An Investigation of the Health Status of Inhabitants of Yellowknife, Northwest Territories, Occupational Health Division, Environmental Health Directorate, Department of Health and Welfare. Ottawa.

Gibson, G., and J. Klinck. 2005. “Canada's Resilient North: The Impact of Mining on Aboriginal Communities." Pimatisiwin: A Journal of Aboriginal and Indigenous Community Health 3(1): 116-139.

Goodall, H. 2006. "Indigenous Peoples, Colonialism, and Memories of Environmental Injustice." In Echoes from the Poisoned Well: Global Memories of Environmental Injustice edited by Sylvia Hood Washington, Paul C. Rosier, and Heather Goodall, 73-95. Oxford: Lexington Books.

Kay, K. 1968. "A Look at the Future of Hazardous Contamination of the Circumpolar Environment." Archives of Environmental Health 17: 653-661.

Keeling, A., and J. Sandlos. 2009. Environmental Justice Goes Underground? Historical Notes from Canada's Northern Mining Frontier. Environmental Justice 2(3): 117-125.

Kirsch, S. 2001. "Environmental Disaster, 'Culture Loss,' and the Law." Current Anthropology 42(2): 167-198. 
Kirsch, S. 2006. Reverse Anthropology: Indigenous Analysis of Social and Environmental Relations in New Guinea. Stanford, CA: Stanford University Press.

Langston, N. 2010. "Toxic Inequities: Chemical Exposures and Indigenous Communities in Canada and the United States." Natural Resources Journal, 50(2): 393-406.

Mackenzie Valley Environmental Impact Review Board (MVEIRB). 2012a. Giant Mine Remediation Environmental Assessment Hearing EA-0809-001, Yellowknife, Sept. 11.

Mackenzie Valley Environmental Impact Review Board (MVEIRB). 2012b. Giant Mine Remediation Environmental Assessment Hearing EA-0809-001, Yellowknife, Sept. 12.

McGregor, D. 2009. “Honouring our Relations: An Anishnaabe Perspective on Environmental Justice." In Speaking for Ourselves: Environmental Justice in Canada edited by J. Agyeman, P. Cole, R. Haluza-DeLay, and P. O'Riley, 27-41. Vancouver: UBC Press.

Mitman, G., Murphy, M., and C. Sellers. 2004. "A Cloud Over History." Osiris $2^{\text {nd }}$ Series 19: 1-17.

Murphy, M. 2008. “Chemical Regimes of Living." Environmental History 13: 695-703.

Nash, L. 2006. Inescapable Ecologies: A History of Environment, Disease, and Knowledge. Berkeley: University of California Press.

Nixon, R. 2011. Slow Violence and the Environmentalism of the Poor. Cambridge: Harvard University Press.

Parlee, B., J. O’Neil, and Lutsel K'e Dene First Nation. 2007. “"The Dene Way of Life': Perspectives on Health from Canada's North." Journal of Canadian Studies 41(3): 112-133.

Rosier, P.C. 2006. "Fond Memories and Bitter Struggles: Concerted Resistance to Environmental Injustices in Postwar Native America." In Echoes from the Poisoned Well: Global Memories of Environmental Injustice, Sylvia Hood Washington, Paul C. Rosier, and Heather Goodall, 35-54. Oxford: Lexington Books.

Sandlos, J., and A. Keeling. 2015. Aboriginal Communities, Traditional Knowledge, and the Environmental Legacies of Extractive Development in Canada. The Extractive Industries and Society 3(2): 278-287. doi:10.1016/j. exis.2015.06.005.

Sandlos, J., and A. Keeling. 2012. "Giant Mine: Historical Summary." Report submitted to the Mackenzie Valley Environmental Impact Review Board. http://www.reviewboard.ca/upload/project_document/EA0809-001_Giant_ Mine_History_Summary.PDF. 
Schlossberg, D., and D. Carruthers. 2010. “Indigenous Struggles, Environmental Justice, and Community Capabilities." Global Environmental Politics 10(4): 12-35.

Tataryn, L. 1978. "Arsenic and Red Tape." National Indian Brotherhood Report.

Tataryn, L. 1979. Dying for a Living. Ottawa: Deneau and Greenberg.

Voyles, T.B. 2015. Wastelanding: Legacies of Uranium Mining in Navajo Country. Minneapolis: University of Minnesota Press.

Walker, G. 2009. Beyond Distribution and Proximity: Exploring the Multiple Spatialities of Environmental Justice. Antipode, 41(4): 614-636

Yellowknives Dene First Nation. 1997. Weledeh Yellowknives Dene: A History. Dettah: Yellowknives Dene First Nation Council.

Yellowknives Dene First Nation. 2008. Presentation from YKDFN, Document submitted to Mackenzie Valley Environmental Impact Review Board. http:// www.reviewboard.ca/upload/project_document/EA0809-001_Presentation_ from_YKDFN.pdf.

Yellowknives Dene First Nation Land and Environment Committee. 2005. “The Giant Gold Mine-Our Story." Report prepared for Giant Mine Remediation Project office, Yellowknife, NWT. 